\title{
Corneal Placido Topography And Its Correlation With The Best Fitting Curve For Non-Astigmatic Eyes
}

\author{
Pateras Evangelos and Karabatsas Konstantinos
}

\begin{abstract}
Placido topographer CSO Phoenix had been used to measure 30 peoples corneas with astigmatism $<0.50$ Dc (University of West Attica) and their refractive maps were taken. The refractive power map was used with measurements taken at the horizontal $\left(180^{\circ}\right)$, vertical $\left(90^{\circ}\right)$, and oblique axes $\left(45^{\circ}\right.$ and $135^{\circ}$ ) for each of these 30 people. The keratometric measurements for $>5 \mathrm{~mm}$ were recorded. The investigation took place at University of West Attica. The results showed that the shape of the cornea varies in the various meridians (e.g. $180^{\circ}$ or $90^{\circ}$ ) and even with oblique meridians (e.g. in the nasal relative to the temporal side) and its curvature correlates with a different equation for each meridian.

Index Terms - Corneal topography, Placido, best fitting curve
\end{abstract}

\section{INTRODUCTION}

The cornea is an optically transparent, dome-shaped anatomic structure, with a slightly curved curvature than that of the sclera, giving the eye a slight tingling on the anterior surface. It is the main refractive agent of the eye and is responsible for $2 / 3$ of its total strength. The remaining $1 / 3$ comes mainly from the crystalline lens with little contribution from the aqueous humor and the vitreous [1],[2].

The average values of its dimensions are as follows:

TABLE I: THE AVERAGE VALUES OF CORNEAS DIMENSIONS

\begin{tabular}{c|c}
\hline \hline Front surface radius & $7.68 \mathrm{~mm}$ \\
\hline Horizontal Diameter & $11.8 \mathrm{~mm}$ \\
\hline Center Thickness & $0.52 \mathrm{~mm}$ \\
\hline Peripheral Thickness & $1.00 \mathrm{~mm}$ \\
\hline \hline
\end{tabular}

Histological the cornea consists of 6 layers of cells: the epithelium, the Bowman membrane, the layer, the Descemet membrane, the pre-Descemet membrane (Dua) and the endothelium [3],[4].

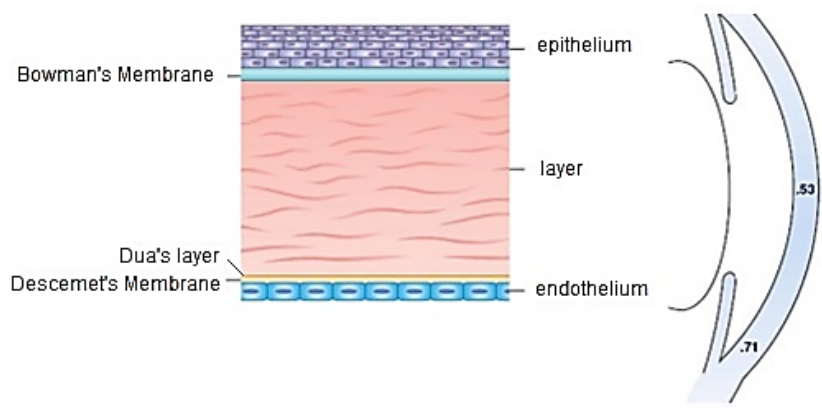

Figure 1: Corneal Layers

Published on February 27, 2020.

Pateras Evangelos, Biomedical Sciences Dept. Course Optics \& Optometry, University of West Attica, Greece.

(e-mail : pateras@uniwa.gr)

Karabatsas K. , Biomedical Sciences Dept. Course Optics \& Optometry, University of West Attica, Greece.

(e-mail : kkarampatsas@uniwa.gr)

\section{METHOD}

The principle of topography operation is based on the principles of keratometry operation, except that it can scan a larger area and not just central $3 \mathrm{~mm}$ as opposed to a simple keratometer [5],[6].

In the placido disc topography we study the deflection of the reflection between the concentric circular rings (mires) formed on the anterior surface of the cornea, thus calculating the radius of curvature of the surface. The mirrored image of the rings is recorded by a digital camera, the computer's program of each device analyzes the data and presents the results in various forms as cartographic maps [7],[8].

Topographic systems are divided into two categories, large and small cones. Large cones have more rings, thus measuring more points, giving more precision. However, due to the long distance organ-cornea, nose and eyelashes are formed giving incomplete data for topography.

On the other hand, small cone systems make measurements very close to the corneal surface, minimizing the "dead" spots. However, this results in fewer rings giving less precision [12],[13].

In addition, topographic systems provide the following information:

- The curvature of any point on the map in diopters.

- Keratometric indications, such as keratometers.

- The average diopter power in each of the light rings.

- Corneal smoothness and symmetry.

- Prediction of visual acuity depending on the smoothness and symmetry of the cornea.

- Optical axis, pupil position and geometric center on map.

- The rectangles but also the real axes of astigmatism on the map.

- Topographic map with a wide variety of forms [9],[10],[16].

Topographic map forms [20],[17] :

1. Absolute scale topographic map

2. Scaled map (normalized scale, adjustable scale)

3. Axial map

4. Local tangential map curvature map

5. Refractive Map

6. Elevation Map

7. Isometric map and 3D map

8. Multiple displays and comparative dioptric map 
Examples of these maps are given in figure 2.

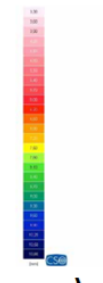

a)
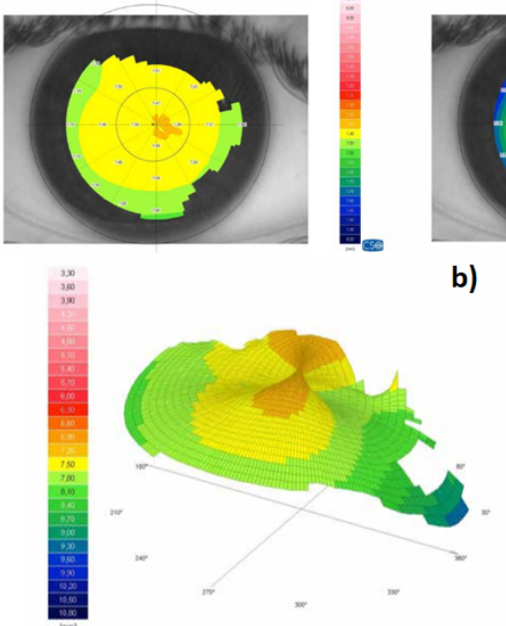

c)

Figure 2: a) Absolute, b) Variable scale (adjustable) topographic maps and c) 3D map.

\section{Normal cornea}

The normal cornea is aspherical and shows a small degree of asymmetry. It is curved in the center with a gradual reduction of curvature (flattening) towards the periphery. There is enantiomorphism (mirror symmetry) between the right and left eye [14],[15],[16].
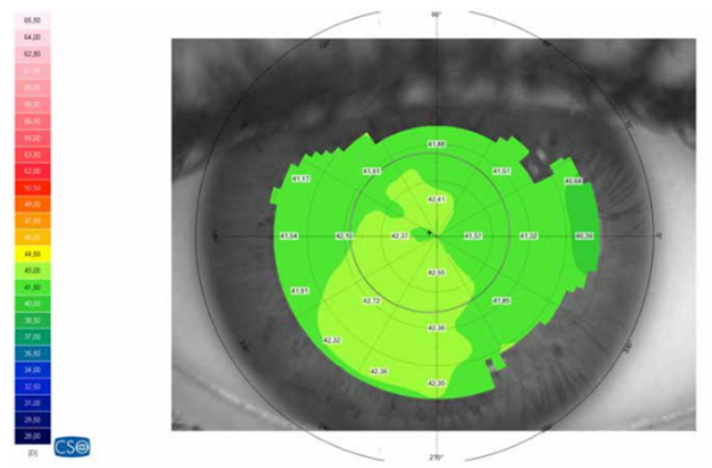

Figure 3: Normal cornea.

Depending on the shape of the central isopters of the topographic map, the shape of the normal cornea is divided into round, oval, symmetrical 8 or hourglass as an asymmetric 8 and anomalous. The symmetrical 8 figures are observed in a cornea with normal astigmatism. When astigmatism is in accordance with the rule, symmetrical 8 figure is on the vertical axis (90), while in the rule of astigmatism in the horizontal (180).

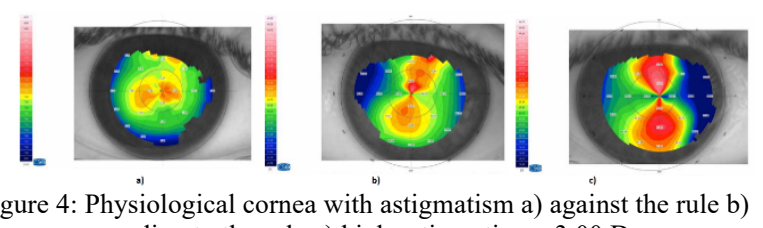

Figure 4: Physiological cornea with astigmatism a) against the rule b) according to the rule c) high astigmatism $>3.00 \mathrm{Dc}$.

What should be noted is that the topography of the cornea is essentially topography of the teardrop layer. Whenever it is abnormal and disturbed (keratoconjunctivitis, malignancies dysfunctions, etc.) the topography becomes inaccurate and relatively unreliable.

In addition, the surface of the cornea is characterized by asphericity.
The cornea is flattened from its top to its periphery and relates to the shape of an elongated shortage.

The shape of the cornea can be described as follows [11],[18],[19] :

$\mathbf{P}=\mathbf{Q}+\mathbf{1}$ and

The eccentricity $Q$ can be described by the following formula $\mathbf{Q}=-\mathrm{e}^{2}$

$\mathrm{SF}$ is the shape factor of the cornea and is equal to

$\mathbf{S F}=\mathbf{e}^{2}$

$\mathrm{SF}$ is also equal to $\mathbf{S F}=\mathbf{1 - p}$

The equation that governs each of these factors is described in Table 1 below.

TABLE 2: THE EQUATION OF THE SHAPE OF THE CORNEA

\begin{tabular}{|c|c|c|c|c|}
\hline & $-\mathrm{e}^{2}$ & $\mathrm{p}$ & $\mathrm{SF}\left(=\mathrm{e}^{2}\right)$ & $\mathrm{Q}\left(=-\mathrm{e}^{2}\right)$ \\
\hline $\mathrm{e}^{2}=$ & $*$ & $1-p$ & $\mathrm{SF}$ & $-Q$ \\
\hline$p=$ & $1-\mathrm{e}^{2}$ & $*$ & 1-SF & $1+Q$ \\
\hline $\mathrm{SF}=$ & $\mathrm{e}^{2}$ & $1-p$ & $*$ & $-Q$ \\
\hline $\mathrm{Q}=$ & $-\mathrm{e}^{2}$ & $\mathrm{p}-1$ & -SF & $*$ \\
\hline
\end{tabular}

A conical section can be a portion of an excess, or parabola, of an ellipse, or part of a circle, and can be fully described using two parameters. The first parameter is the main (central) radius of curvature $r_{0}$ and the second parameter is the eccentricity.

The simplest way to describe a conical section is by using the Baker equation where,

$$
p=\frac{\left(2 r_{0} * x-y^{2}\right)}{y^{2}}
$$

$\mathrm{p}=$ coefficient of shape

$\mathrm{r}_{0}=$ center radius of curvature $(\mathrm{mm})$

$\mathrm{x}=$ sagittal depth at a length determined by the chord (mm)

$\mathrm{y}=$ half of the chord length $(\mathrm{mm})$

Many current topographers use this equation as a basis for calculating the shape of the cornea and the various markers. All these conic sections are described by a single equation:

$$
\mathbf{y}^{2}=2 \mathbf{r}_{0} \mathbf{x}-\mathbf{p} \mathbf{x}^{2}
$$

Where $r_{0}$ is the radius of curvature of the surface at the top and the type of conic section depends on the value of $p$, as shown in the figure, $p$ is the number whose value determines and the type of surface.

For $\mathrm{p}>1$ we have a vertical deficiency

For $\mathrm{p}=0$ we have a circle

For $\mathrm{p}<1$ but $>0$ we have a horizontal deficiency

For $\mathrm{p}=0$ we have the so-called parabola and

For $\mathrm{p}<0$ we have hyperbola

When the conical sections are rotated around their $\mathrm{x}$-axis axes, the solid shapes created are known as cones. 


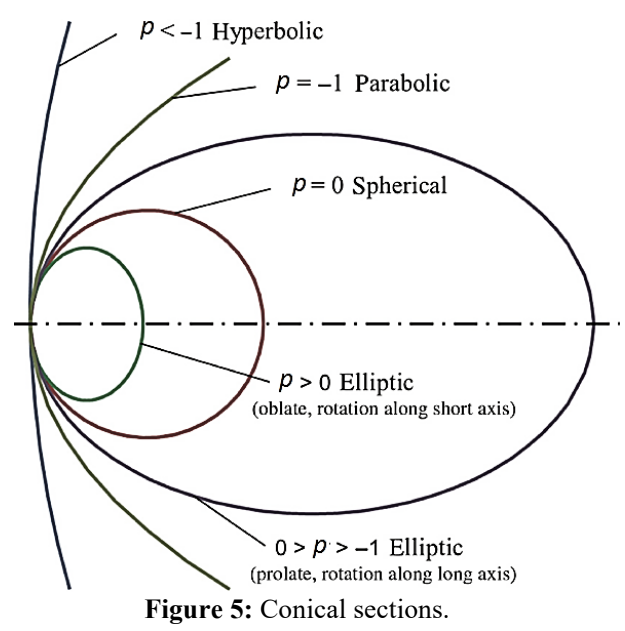

III. PuRpose

Using Placido topographer CSO Phoenix, 30 people (University of West Attica) were measured and refractive maps were taken from the corneas of those participants.

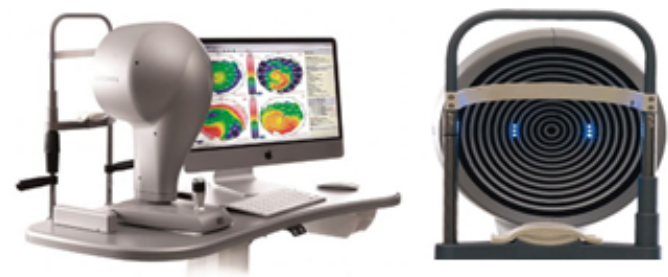

Figure 6: Placido topographer CSO Phoenix
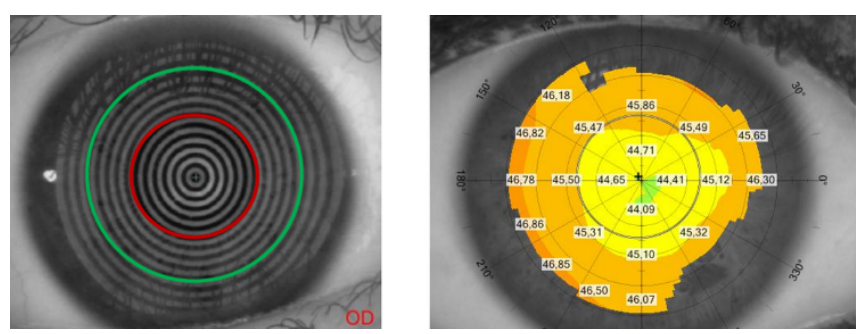

Figure 7: Placido-Based Topography \& Refractive Map (Placido topographer CSO Phoenix)

We excluded map samples where astigmatism in the central $3 \mathrm{~mm}$ measurement was $<0.50 \mathrm{Dc}$. The refractive power was taken at the horizontal $\left(180^{\circ}\right)$, vertical $\left(90^{\circ}\right)$, and oblique axes $\left(45^{\circ}\right.$ and $\left.135^{\circ}\right)$ for each of the 30 people (University of West Attica). Also the average keratometric measurements for $3 \mathrm{~mm}$ were recorded.

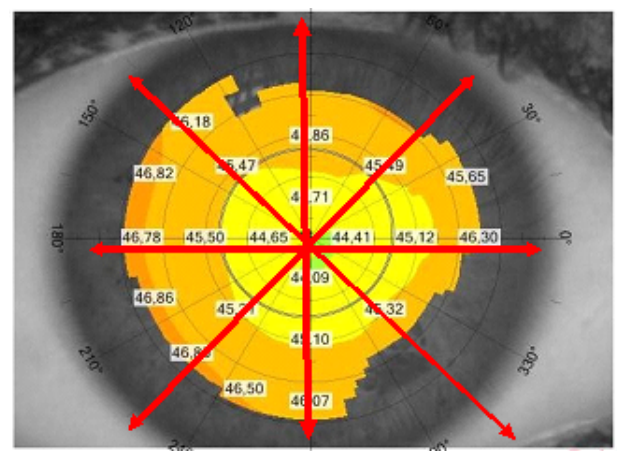

Figure 8: Refractive power at $180^{\circ}, 90^{\circ}, 45^{\circ}, 135^{\circ}$

\section{RESUlTS}

Taken the refractive powers for example as it is seen in Fig.8, firstly at $180^{\circ}(46.78,45.50,44.65,44.41,45.12,46.30)$ at 90 $\circ(45.86,44.71,44.09,45.10,46.07)$ at $45{ }^{\circ}(45.49,45.51$, $46.85)$ and at $135 \circ(46.18,45.47,45.32)$ we tried to find using the best fitting curve equation that represents the curve that each meridian had according to the data selected.

The following diagrams show the best fitting curve equation for the $180^{\circ}, 90^{\circ}, 45^{\circ}, 135^{\circ}$.

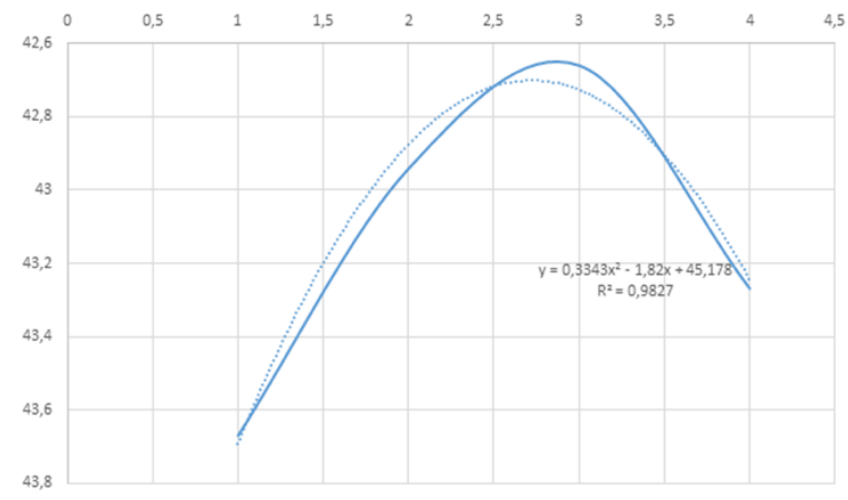

Figure 9: The polynomial best fitting curve matching the curvature of the

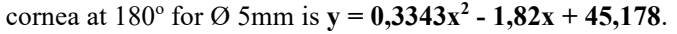

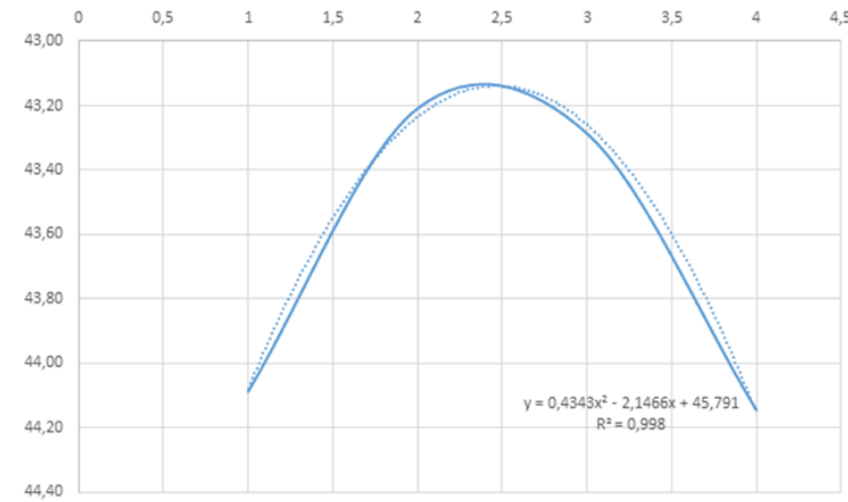

Figure 10: The polynomial best fitting curve matching the curvature of the cornea at $90^{\circ}$ for $\varnothing 5 \mathrm{~mm}$ is $\mathbf{y}=\mathbf{0 , 4 3 4 3 \mathbf { x } ^ { 2 }} \mathbf{- 2 , 1 4 6 6} \mathbf{x}+\mathbf{4 5 , 7 9 1}$.

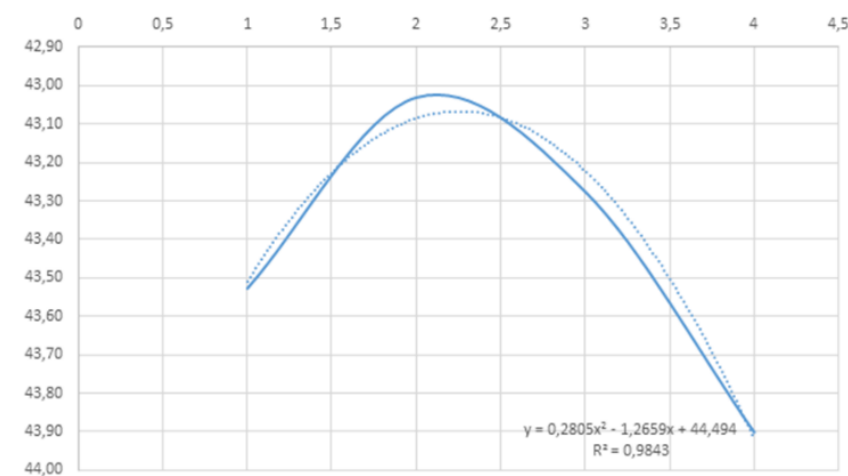

Figure 11: The polynomial best fitting curve matching the curvature of the cornea at $45^{\circ}$ for $\varnothing 5 \mathrm{~mm}$ is $\mathbf{y}=\mathbf{0 , 2 8 0 5} \mathbf{x}^{2} \mathbf{- 1 , 2 6 5 9 x}+\mathbf{4 4 , 4 9 4}$. 


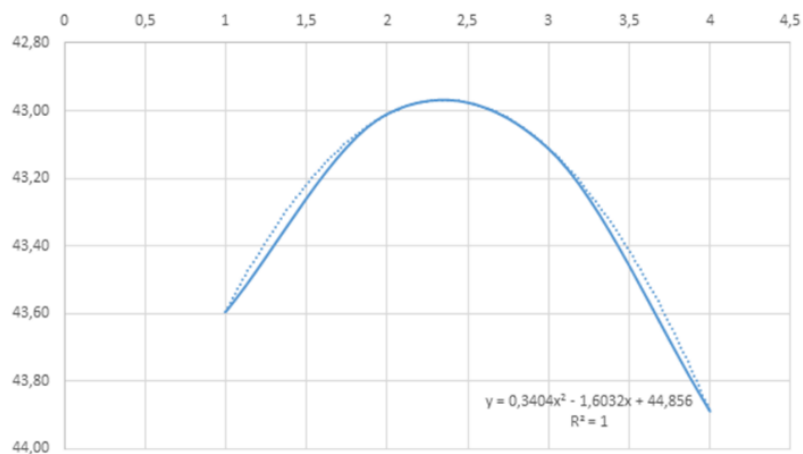

Figure 12: The polynomial best fitting curve matching the curvature of the

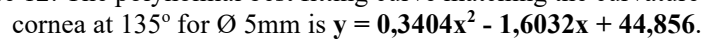

\section{CONCLUSION}

The results showed that the shape of the cornea varies in the various meridians (e.g. $180^{\circ}$ or $90^{\circ}$ ) and even with oblique meridians (e.g. in the nasal relative to the temporal side) and does not have the same curvature. This is probably to the anatomy of the cranial bones orbit and the different pressure that the eyelids generate on the corneal surface (more nasally, vertical and less temporal, horizontal).

\section{REFERENCES}

[1] Davson H. "Physiology of the Eye", 5th ed. New York: Pergamon Press, 1991 .

[2] Le Grand Y. "Physiological Optics" New York: Springer-Verlag, 1980.

[3] Helmholtz HV, Southall JPC. "Helmholtz's Treatise on Physiological Optics". Rochester, NY: The Optical Society of America, 1924.

[4] Pedrotti LS, Pedrotti FL. Optics and Vision. Upper Saddle River, NY: Prentice Hall, 1998.

[5] El Hage SG. "A new conception of the corneal topology and its application". Optica Acta 1972; 19:431-3.

[6] Rabinowittz YS, Wilson SE, Klyce SD. "Color Atlas of Topography: Interpreting Videokeratography”. New York: Igaku-Shoin, 1993.

[7] Mattioli R, Tripoli NK. "Corneal geometry reconstruction with the Keratron videokeratographer”. Optom Vis Sci 1997; 74:881-94.

[8] Roberts C. "The accuracy of 'power' maps to display curvature data in corneal topography systems". Invest Ophthalmol Vis Sci 1994; 35:3525-32.

[9] Klein SA, Mandell RB. "Axial and instantaneous power conversion in corneal topography” Invest Ophthalmol Vis Sci 1995; 36:2155-9.

[10] Swartz, Tracy; Marten, Lisa; Wang, Ming "Measuring the cornea: the latest developments in corneal topography" Current Opinion in Ophthalmology: July 2007 - Volume 18 - Issue 4 - p 325-333

[11] Courville CB, Smolek MK, Klyce SD. "Contribution of the ocular surface to visual optics". Exp Eye Res 2004; 78: 417-25.

[12] James S. Wolffsohn, Frank Eperjesi "Clinical Instrumentation in Contact Lens Practice", Contact Lenses (Sixth Edition), 2019

[13] Anderson D, Kojima R. "Topography: A clinical pearl” Optom Manag $2007 \mathrm{Feb} ; 42(2): 35$.

[14] Rio-Cristobal A, Martin R. "Corneal assessment technologies: Current status” Surv Ophthalmol. 2014;59:599-614

[15] Brody J, Waller S, Wagoner M. "Corneal topography: History, technique, and clinical uses” Int Ophthalmol Clin. 1994;34:197-207

[16] Ortiz-Toquero S, Rodriguez G, de Juan V, Martin R. "Repeatability of placido-based corneal topography in keratoconus" Optom Vis Sci. 2014;91:1467-73.

[17] Belin MW, Khachikian SS. "An introduction to understanding elevation-based topography: How elevation data are displayed - A review" Clin Exp Ophthalmol. 2009;37:14-29

[18] de Jong T, Sheehan MT, Dubbelman M, Koopmans SA, Jansonius NM. "Shape of the anterior cornea: Comparison of height data from 4 corneal topographers" J Cataract Refract Surg. 2013;39:1570-80

[19] Nathan Efron "Anterior eye examination" Contact Lens Complications (Third Edition), 2012

[20] Rachel F. et al. "Applications of corneal topography and tomography: a review: Applications of corneal topography and tomography" Clinical and Experimental Ophthalmology 46(2) December 2017

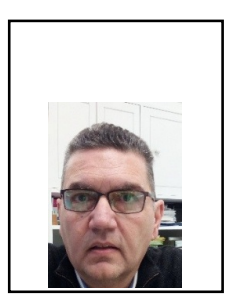

Dr. Pateras Evangelos

Associate professor in the field of ophthalmic multifocal lens technology. OpticianOptometrist, Master's Degree (Mphil) and PhD from Vision Science \& Optometry Department of Aston University Birmingham, where he was a Fellow of the State Scholarship Foundation (IKY). Worked as a Clinical Demonstrator in the Ophthalmic Laboratory, Aston University Contact Lenses and Optometric Clinics and participated in GNA Ophthalmic Surgery. He is an Academic Advisor at NARIC. Member of the European Academy of Optometrists (E.A.O.O). Member of the British Contact Lens Applicants Organization (B.C.L.A). Member of Ciba Vision's "Elite Club" as a leading contact lens implementer. He has participated in workshops and conferences in Greece and abroad. He teaches in the postgraduate program in Optics \& Optometry. He has authored numerous works, with articles published in Greek and foreign journals, and 5 books in the field of Optics \& Optometry. 